\title{
EFFECT OF HEIGHT, TILT AND TWIST ANGLES OF AN ACTIVE REFLECTANCE SENSOR ON NDVI MEASUREMENTS
}

\author{
Vinícius Stocker', Eduardo G. de Souza ${ }^{2 *}$, Jerry A. Johann¹, Humberto M. Beneduzzi³, \\ Franciléia de O. e Silva ${ }^{1}$
}

${ }^{2 *}$ Corresponding author. Western Paraná State University (UNIOESTE)/ Cascavel - PR, Brazil.

E-mail: eduardo.souza@unioeste.br | ORCID ID: http://orcid.org/0000-0003-3029-8939

\section{KEYWORDS}

nitrogen fertilization, precision agriculture, GreenSeeker, NDVI.

\begin{abstract}
The application of nitrogen $(\mathrm{N})$ fertilizer is complex and expensive, so its correct management has financial and environmental benefits. The use of optical proximity sensors is a promising technique. However, the movement of the agricultural machinery or of the person carrying the sensor will result in height differences and/or different tilt and twist angles with respect to the canopy. We considered whether these variations would affect the reflectance measurement. In this study, we took normalized difference vegetation index (NDVI) readings of a wheat canopy, to which $90 \mathrm{~kg} \mathrm{ha}^{-1}$ of urea had been applied in stage 5, and observed the NDVI in stages 6, 8 and 10.5. We also tested soybeans, to which $90 \mathrm{~kg} \mathrm{ha}^{-1}$ of urea had been applied in stage R1, and took NDVI readings in stages R2 and R5. Our goal was to study the effects of the position of an active reflectance sensor (GreenSeeker) on the NDVI index at different heights and at different angles to the canopy. We observed that the height of the sensor affected the NDVI depending on the stage of the plant and that angles up to $15^{\circ}$ of the sensor did not directly affect the readings.
\end{abstract}

\section{INTRODUCTION}

The correct application of nutrients to the soil may contribute to a reduction of the possible environmental impacts of agricultural activity. Both the reduction of pollution and the leaching of applied nutrients results in minor impacts (Schieffer \& Dillon, 2015). Nitrogen is an essential component for the maintenance of the life of both animals and plants, and it is a constituent of amino acids, proteins and nucleic acids (Cherkasov et al., 2015), therefore its correct management is essential for profitability with a low environmental impact.

The measurement of $\mathrm{N}$ available to the crop directly on the soil is not a practical method, according to Drake et al. (2015), because it is easily lost by leaching, volatilization and denitrification in the soil. Padilla et al. (2014) and Amaral et al. (2015) suggests the use of optical proximity sensors to indirectly read the level of $\mathrm{N}$ from the optical properties of the leaves as a promising alternative. According to Singh (2015), the chlorophyll in the leaves absorbs part of the radiation at wavelengths in the red range and the leaf structure reflects part of the radiation in the infrared range, so there is a correlation between the NDVI response and the $\mathrm{N}$ present in the soil. The stress level of the plant can be estimated by its $\mathrm{N}$ content derived from the ratio of the absorbed and reflected radiation (Schwerz et al., 2016).

Crusiol et al. (2013) investigated the influence of sensor heights $(0.40,0.60,0.80,1.00$, and $1.20 \mathrm{~m}$ above canopy) on NDVI measurements by using a GreenSeeker ${ }^{\circledR}$ and observed a consistent NDVI decrease with increased height; further, it was determined that a fixed height of sensor should be used to obtain better results. Also using a GreenSeeker, Kim et al. (2010) found, in a laboratory setting, that the acceptable range of sensor height was $1.0-$ $1.8 \mathrm{~m}$ (0.026 m standard deviation).

According to Kim et al. (2010), although an active sensor uses modulated radiation that can be differentiated from ambient illumination to validate data and increase accuracy, the sensor characteristics must be well understood

\footnotetext{
${ }^{1}$ Western Paraná State University (UNIOESTE)/ Cascavel - PR, Brazil.

${ }^{3}$ Paraná Federal Institute (IFPR)/ Foz do Iguaçu - PR, Brazil.
} 
and investigated in potential target conditions with various plant leaf coverage. They conduced one of a few studies in literature that are related to the tilt angle of the sensor in relation to the canopy. Their laboratory study evaluated a GreenSeeker sensor under different illumination and target conditions: $30-100 \%$ leaf coverage, $\pm 0.15 \mathrm{~m}$ off-center with $30 \%$ leaf coverage, a $1.0-1.8 \mathrm{~m}$ standoff distance, and a $0-50^{\circ}$ tilt angle. They found that differences of NDVI value were not observed within $0-60^{\circ}$ solar zenith angles. There were also no significant effects due to changes in temperature and artificial illumination in a chamber.

Tubana et al. (2011) evaluated the relationship between NDVI and simple ratio (SR) measured at different view angles using an active sensor (GreenSeeker) at onemeter height above the canopy considering rice biomass and grain yield. Sensor readings and biomass at panicle differentiation (PD) and 50\% heading, and grain yield were collected from multiple variety $\times \mathrm{N}$ rate trials established in different rice-producing areas of the mid-southern United States in 2009 and 2010. They concluded that the NDVI and SR viewed at various angles were higher in general than the nadir angle $\left(0^{\circ}\right)$, implying that the rice canopy reflectance spectra was altered such that the sensor captured higher fractions of green vegetation than other scene components such as the water background and shade. However, varying the angle, provided no evident improvement of the performance of NDVI and SR as predictors of the biomass and grain yield.

Beneduzzi et al. (2017) investigated the temporal variability of NDVI measured by a GreenSeeker in both soybean and wheat crops. The NDVI data were collected using a GreenSeeker sensor every 15 minutes for 12 or 14 consecutive hours. The NDVI was negatively influenced by irradiation in all experiments with soybean and wheat, showing higher values at the beginning and end of the day. Changes in cloud cover also affected the NDVI values during the experiments.

Furthermore, considering that: 1) The movement of agricultural machinery or someone carrying the sensor will result in height differences and/or different tilt and twist angles with respect to the canopy, and 2) No investigations of this phenomenon have been done in field, the objective

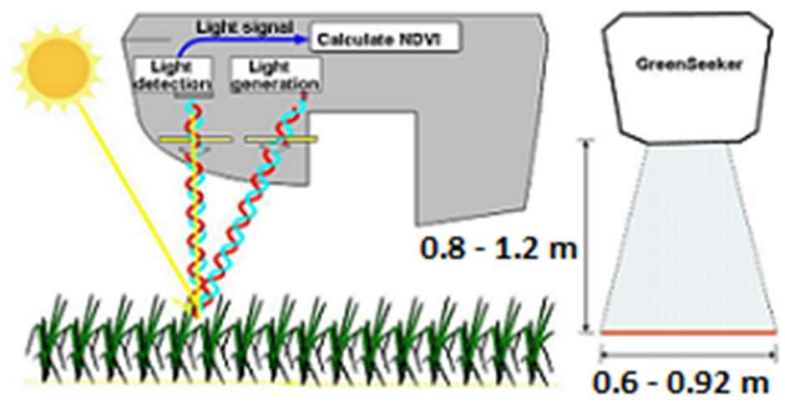

(a) this paper was to study the influence of height and tilt and twist angles of an active reflectance sensor (GreenSeeker) on its NDVI measurements.

\section{MATERIAL AND METHODS}

This research was carried out in a commercial agricultural area located in the city of Céu Azul/PR, whose area has been cultivated in the no-tillage system for more than 10 years. Two separate fields in the area were used for the experiment. The first field has an approximate geographical location of $25^{\circ} 06^{\prime} 52^{\prime \prime} \mathrm{S}$ latitude and $53^{\circ} 50^{\prime} 01^{\prime \prime} \mathrm{W}$ longitude with a soybean crop and the second has an approximate geographical location of $25^{\circ} 06^{\prime} 52^{\prime \prime} \mathrm{S}$ latitude and $53^{\circ} 50^{\prime} 01^{\prime \prime} \mathrm{W}$ longitude with a wheat crop. Both fields have an average altitude of 750 meters, with a soil typical of the Dystroferric Red Latosol type (Embrapa, 2018). The climate is of the Cfa type according to the Köppen-Geiger classification; it is a humid temperate climate with hot summers and a tendency for more rain in this period than at other times (Alvares et al., 2013). The wheat cultivar used was Biotrigo Iguaçu sown in May 2015, and the readings were taken in June and July 2015. The soybean cultivar used was Syngenta 1359 sown in October 2015, and the readings were taken in December 2015 and January 2016.

The NDVI measurements were performed with an active GreenSeeker 505 reflectance sensor (Trimble, Sunnyvale, USA, Figure 1a) supported by aluminum tripod developed to ensure the same positioning of the sensor for all of the readings throughout the experiment. The support was constructed in an $8 \mathrm{~mm}$ aluminum plate and the assembly was made with 4 and 6-mm screws. This material was chosen because of its lightness, ease of machining and the low cost (Figure 1b). Tilt was made by a fixed screw axis, which was locked in the reading positions by previously calibrated holes and secured by metal locks to keep the support still. The twist movement was made by linear bearings on metal shafts, similar to those used in 3D printers and milling machines, which were also locked in position by holes and latches.

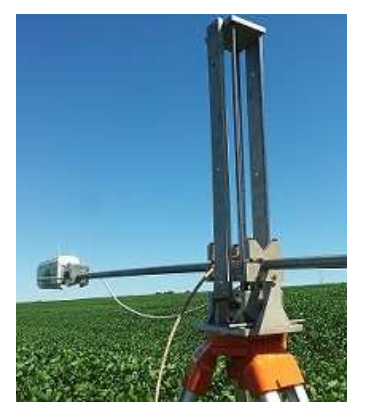

(b)

FIGURE 1. a) Structure of the active optical sensor. b) Sensor mounted on the positioning support. Source: (a) adapted from Kim et. al (2010).

The readings were taken at $0.8,1.0$ and 1.2-meter heights using the positioning recommended in the sensor manual. The manufacturer's recommendation is to use the sensor parallel to the sensing area. However, it is known that it is practically impossible to keep the sensor parallel to the sensing area, and it was thought that one inclination to $15 \%$ was feasible. Different angles could be tested (i.e., more than $15 \%$ inclination), but a previous study carried by the authors has found out that these inclinations did not significantly affect the sensor reading. There are a few studies in the literature that have tested this variable, including that of Tubana et al. (2011). The twist and tilt 
angles for the readings were adopted as $15^{\circ}$ for both up/down and right/left inclinations. Figure 2 shows the sensor positions discussed in this study, where the green line represents the highest canopy position.

The duration of each reading was set at ten (10) seconds. The sensor performs ten (10) readings per second, and 100 readings per position were performed, and the mean was calculated. Several authors, such as Souza et al. (2010) and Beneduzzi et al. (2017) have already observed the effect of the reading time of an active reflectance sensor. Therefore, is decided to perform readings during the day, from 7 am to $7 \mathrm{pm}$ with a 30minute interval between the readings, for a total of 25 samples for each position. Was also noted the incident solar radiation on the sensor for each reading, with the help of an Instrutherm MES-100 pyranometer.

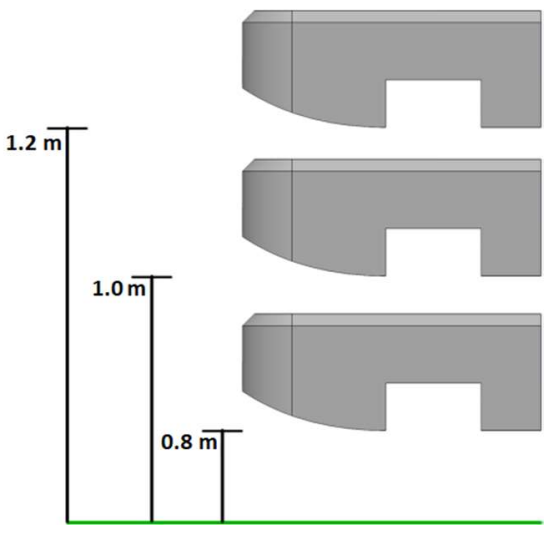

(a) Sensor heights

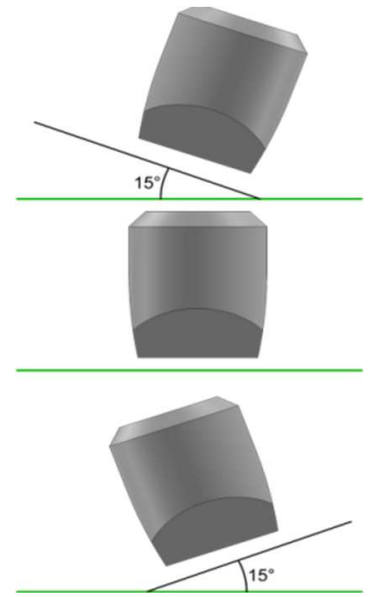

(b) Twist angles

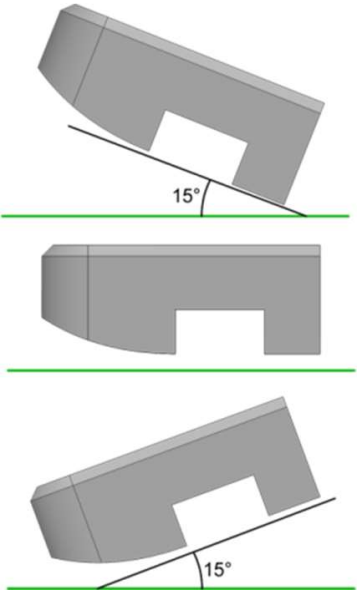

(c) Tilt angles

FIGURE 2. Sensor positions at the three experiments varying sensor heights (a), twist (b) and tilt angles (c). The green line represents the highest canopy position.

For the soybean crop, $90 \mathrm{~kg} \mathrm{ha}^{-1}$ of $\mathrm{N}$ was applied during the R1 stage (Schmitt et al., 2001) in the form of Super N Fertipar urea, with a 46-0-0 formulation so that there was no nutrient deficiency in the plants. The readings were taken in the R2 and R5 stages. The R2 stage was chosen due to its proximity to the stage at which the $\mathrm{N}$ was applied, and the R5 stage was chosen because it is the stage at which the plant begins the transfer of $\mathrm{N}$ to the grain (Ritchie et al., 1985).

The best stage for the application of nitrogen fertilization in a wheat crop is stage 5 (Walsh et al., 2012). Was applied a rate of $90 \mathrm{~kg} \mathrm{ha}^{-1}$ of $\mathrm{N}$ in the form of Super $\mathrm{N}$ Fertipar urea with a 46-0-0 formulation. Cao et al. (2015) took readings in stages 6 and 10.5. In this experiment, was opted to take readings in stages 6,8 and 10.5 . The stage 6 was chosen due to its proximity to the stage at which $\mathrm{N}$ was applied and the others to have a time interval between the readings.

After obtaining the field readings, an exploratory statistical analysis was done to verify the normality of the data obtained. The coefficient of variation $(\mathrm{CV})$ was determined and classified according to Pimentel \& Garcia (2002): $\mathrm{CV} \leq 10 \%$, low; $10 \%<\mathrm{CV} \leq 20 \%$, medium; $20 \%$ $<\mathrm{CV} \leq 30 \%$, high; and CV $>30 \%$, very high. Statistica 13 software was used to make charts and perform statistical tests. Boxplots were also created to compare the means of heights and angles for the wheat and soybean crops and to investigate outliers. An outlier is a value that lies in a data series on its extremes; as such, this value is either very small or large and, thus, can affect the overall observation made from the data series. According to Hubert \& Van der Veeken (2008) the probability for a data point to lie beyond the interval [Q1 - 1.5 IQR, Q3 + 1.5 IQR] is approximately $0.7 \%$, where IQR is the interquartile range, Q1 is the first and Q3 the third quartile. As per the basic standards followed by statisticians, this interval is a convenient definition of an outlier and can be easily applied using the standard boxplot.

We compared the NDVI readings as follows: heights of $1.2 \mathrm{~m}$ and $0.8 \mathrm{~m}$ were compared to $1 \mathrm{~m}$ and all stages and crops were considered. The angles of $15^{\circ}$ upwards and $15^{\circ}$ downwards were compared to the central position compared to $1 \mathrm{~m}$ for all stages and crops, and finally, the angles of $15^{\circ}$ to the right and $15^{\circ}$ to the left were compared to the center position compared to $1 \mathrm{~m}$ for all stages and crops. The Willmott's advanced concordance index (d) (Willmott et al., 2012) was used to calculate the similarity between two NDVI measurements, as described by Equation 1. According to this approach, a value of $d$ of 0.5 , for example, indicates that the sum of the error-magnitudes is one half of the sum of the perfect-model-deviation and observeddeviation magnitudes. When $d=0.0$, it signifies that the sum of the magnitudes of the errors and the sum of the perfect-model-deviation and observed-deviation magnitudes are equivalent. When $d=-0.5$, it indicates that the sum of the error-magnitudes is twice the sum of the perfect-model-deviation and observed-deviation magnitudes. Values of $d$ near -1.0 can mean that the modelestimated deviations about 0 are poor estimates of the observed deviations. Mean bias error (MBE), mean absolute error (MAE), and root mean squared error (RMSE) were used to evaluate the errors of different NDVI readings (Equations 2, 3, and 4).

$$
d=\left\{\begin{array}{c}
1-\frac{\sum_{i=1}^{n}\left|E_{i}-O_{i}\right|}{2 \sum_{i=1}^{n}\left|O_{i}-\bar{O}\right|}, \text { where } \\
\sum_{i=1}^{n}\left|E_{i}-O_{i}\right| \leq 2 \sum_{i=1}^{n}\left|O_{i}-\bar{O}\right| \\
\frac{2 \sum_{i=1}^{n}\left|O_{i}-\bar{O}\right|}{\sum_{i=1}^{n}\left|E_{i}-O_{i}\right|}-1, \text { where } \\
\sum_{i=1}^{n}\left|E_{i}-O_{i}\right|>2 \sum_{i=1}^{n}\left|O_{i}-\bar{O}\right|
\end{array}\right.
$$




$$
\begin{aligned}
& M B E=\frac{\sum_{i=1}^{n}\left(E_{i}-O_{i}\right)}{n} \\
& M A E=\frac{1}{n} \sum_{i=1}^{n}\left|E_{i}-O_{i}\right| \\
& R M S E=\sqrt{\frac{1}{n} \sum_{i=1}^{n}\left(E_{i}-O_{i}\right)}
\end{aligned}
$$

Where,

$\mathrm{N}$ is the number of readings;

$\mathrm{E}$ is the NDVI value to be compared, and

$\mathrm{O}$ is the value of the NDVI taken as default.

\section{RESULTS AND DISCUSSION}

The CV of the NDVI indices (Table 1) for the functions of the crop and the GreenSeeker sensor heights were considered low, therefore, it was observed that the data was homoscedastic. A slight decrease in the mean values was also observed as the sensor height increased for all stages, as well as a slight increase in the standard deviation (except for stage 8 for wheat). The descriptive statistics for the tilt angles (up and down by $15^{\circ}$ ) again had $\mathrm{CV}$ values of less than $10 \%$, therefore, the data was homoscedastic for all crops and positions. The data for twist angles (right and left in $15^{\circ}$ ) were also homoscedastic for all crops and positions, indicated by a CV value less than $10 \%$. The mean NDVI for wheat in stage 10.5 was lower than the other readings, which could be explained by the advanced development cycle of the crop at the time the reading was taken.

The mean bias error (MBE), mean absolute error (MAE), and root mean squared error (RMSE) of different NDVI readings are presented in Table 1 . The greatest biases were: -0.042 (underestimation) for stage R5 soybean up tilt and 0.069 (overestimation) for stage 10.5 wheat up tilt. The smallest global error corresponded to a MAE of 0.011 and a RMSE of 0.014, which were obtained in the majority of the R2 and R5 soybean stages. The greatest global error corresponded to a MAE of 0.076 and a RMSE of 0.086 ,

\begin{tabular}{|c|c|c|c|c|c|c|c|c|c|c|}
\hline Crop & Position & Min. & Mean & Median & Max. & S. D. & C.V. & MBE & MAE & RMSE \\
\hline \multirow{8}{*}{ Stage 6 wheat } & $1.0 \mathrm{~m}$ center & 0.800 & 0.844 & 0.852 & 0.886 & 0.022 & 0.026 & - & - & - \\
\hline & $0.8 \mathrm{~m}$ & 0.789 & 0.847 & 0.846 & 0.891 & 0.020 & 0.024 & 0.003 & 0.022 & 0.028 \\
\hline & $1.2 \mathrm{~m}$ & 0.769 & 0.817 & 0.809 & 0.860 & 0.030 & 0.037 & -0.027 & 0.039 & 0.047 \\
\hline & Down tilt & 0.826 & 0.852 & 0.845 & 0.900 & 0.020 & 0.024 & 0.008 & 0.021 & 0.026 \\
\hline & Up tilt & 0.793 & 0.840 & 0.839 & 0.894 & 0.028 & 0.034 & -0.004 & 0.023 & 0.030 \\
\hline & Right twist & 0.775 & 0.844 & 0.844 & 0.900 & 0.026 & 0.031 & 0.000 & 0.025 & 0.033 \\
\hline & Left twist & 0.815 & 0.849 & 0.848 & 0.905 & 0.026 & 0.031 & 0.005 & 0.024 & 0.030 \\
\hline & Mean & 0.795 & 0.842 & 0.840 & 0.891 & 0.025 & 0.030 & -0.003 & 0.026 & 0.032 \\
\hline \multirow{8}{*}{ Stage 8 wheat } & $1.0 \mathrm{~m}$ center & 0.826 & 0.846 & 0.848 & 0.870 & 0.010 & 0.012 & - & - & - \\
\hline & $0.8 \mathrm{~m}$ & 0.802 & 0.849 & 0.851 & 0.879 & 0.018 & 0.021 & 0.005 & 0.023 & 0.029 \\
\hline & $1.2 \mathrm{~m}$ & 0.812 & 0.840 & 0.838 & 0.866 & 0.013 & 0.015 & -0.004 & 0.027 & 0.034 \\
\hline & Down tilt & 0.845 & 0.864 & 0.867 & 0.880 & 0.007 & 0.009 & 0.020 & 0.030 & 0.037 \\
\hline & Up tilt & 0.822 & 0.856 & 0.859 & 0.882 & 0.016 & 0.018 & 0.012 & 0.027 & 0.034 \\
\hline & Right twist & 0.832 & 0.853 & 0.854 & 0.871 & 0.009 & 0.010 & 0.009 & 0.028 & 0.034 \\
\hline & Left twist & 0.829 & 0.856 & 0.859 & 0.875 & 0.012 & 0.014 & 0.012 & 0.028 & 0.035 \\
\hline & Mean & 0.824 & 0.852 & 0.854 & 0.875 & 0.012 & 0.014 & 0.009 & 0.027 & 0.034 \\
\hline \multirow{8}{*}{ Stage 10.5 wheat } & $1.0 \mathrm{~m}$ center & 0.698 & 0.771 & 0.772 & 0.840 & 0.042 & 0.055 & - & - & - \\
\hline & $0.8 \mathrm{~m}$ & 0.741 & 0.778 & 0.770 & 0.830 & 0.027 & 0.035 & 0.008 & 0.025 & 0.031 \\
\hline & $1.2 \mathrm{~m}$ & 0.680 & 0.753 & 0.752 & 0.820 & 0.049 & 0.064 & -0.018 & 0.031 & 0.038 \\
\hline & Down tilt & 0.755 & 0.803 & 0.801 & 0.868 & 0.032 & 0.039 & 0.032 & 0.036 & 0.044 \\
\hline & Up tilt & 0.725 & 0.781 & 0.774 & 0.840 & 0.038 & 0.049 & 0.069 & 0.076 & 0.086 \\
\hline & Right twist & 0.717 & 0.767 & 0.761 & 0.819 & 0.031 & 0.041 & -0.004 & 0.027 & 0.034 \\
\hline & Left twist & 0.726 & 0.779 & 0.767 & 0.845 & 0.039 & 0.050 & 0.008 & 0.027 & 0.033 \\
\hline & Mean & 0.720 & 0.776 & 0.771 & 0.837 & 0.037 & 0.048 & 0.016 & 0.037 & 0.044 \\
\hline \multirow{8}{*}{ Stage R2 soybean } & $1.0 \mathrm{~m}$ center & 0.859 & 0.898 & 0.900 & 0.915 & 0.014 & 0.015 & - & - & - \\
\hline & $0.8 \mathrm{~m}$ & 0.884 & 0.901 & 0.899 & 0.926 & 0.010 & 0.011 & 0.004 & 0.012 & 0.015 \\
\hline & $1.2 \mathrm{~m}$ & 0.841 & 0.886 & 0.885 & 0.916 & 0.021 & 0.024 & -0.012 & 0.016 & 0.020 \\
\hline & Down tilt & 0.868 & 0.896 & 0.898 & 0.919 & 0.014 & 0.016 & -0.002 & 0.011 & 0.014 \\
\hline & Up tilt & 0.042 & 0.054 & 0.053 & 0.077 & 0.009 & 0.017 & 0.000 & 0.011 & 0.014 \\
\hline & Right twist & 0.855 & 0.893 & 0.900 & 0.915 & 0.017 & 0.020 & -0.005 & 0.011 & 0.014 \\
\hline & Left twist & 0.870 & 0.898 & 0.896 & 0.918 & 0.015 & 0.016 & 0.000 & 0.011 & 0.014 \\
\hline & Mean & 0.746 & 0.775 & 0.776 & 0.798 & 0.014 & 0.017 & -0.003 & 0.012 & 0.015 \\
\hline \multirow{8}{*}{ Stage R5 soybean } & $1.0 \mathrm{~m}$ center & 0.850 & 0.879 & 0.874 & 0.925 & 0.019 & 0.022 & - & - & - \\
\hline & $0.8 \mathrm{~m}$ & 0.862 & 0.883 & 0.878 & 0.915 & 0.014 & 0.016 & 0.004 & 0.011 & 0.014 \\
\hline & $1.2 \mathrm{~m}$ & 0.820 & 0.865 & 0.858 & 0.946 & 0.033 & 0.038 & -0.015 & 0.021 & 0.025 \\
\hline & Down tilt & 0.832 & 0.875 & 0.881 & 0.913 & 0.026 & 0.030 & -0.004 & 0.016 & 0.019 \\
\hline & Up tilt & 0.771 & 0.837 & 0.830 & 0.934 & 0.043 & 0.051 & -0.042 & 0.045 & 0.053 \\
\hline & Right twist & 0.858 & 0.885 & 0.878 & 0.927 & 0.019 & 0.022 & 0.006 & 0.011 & 0.014 \\
\hline & Left twist & 0.849 & 0.874 & 0.868 & 0.922 & 0.020 & 0.023 & -0.005 & 0.012 & 0.015 \\
\hline & Mean & 0.835 & 0.871 & 0.867 & 0.926 & 0.025 & 0.029 & -0.009 & 0.019 & 0.023 \\
\hline
\end{tabular}
which were obtained in stage 10.5 wheat up tilt.

TABLE 1. Descriptive statistics of the NDVI according to the crop, the height, and the tilt and twist angle of the GreenSeeker sensor.

D. P.: Standard Deviation; C. V.: Coefficient of Variation; MBE: mean bias error. MAE: Mean Absolute Error. RMSE: Root Mean Squared Error. MBE, MAE, and RMSE are calculated using " $1.0-\mathrm{m}$ center" as reference. 
The values for solar radiation during the readings at three heights $(0.8,1.0$, and $1.2 \mathrm{~m})$ (Figures $3 \mathrm{~b}, 3 \mathrm{~d}, 3 \mathrm{f}, 3 \mathrm{~h}$, and $3 \mathrm{j}$ ) show a greater variation of amplitude and were smaller during the first hours of the morning and the end of the afternoon; visually, however, it can be seen that these values were not significantly different among sensor heights. When the radiation readings were compared to the NDVI readings (Figures 3a, 3c, 3e, 3g and 3i), the NDVI showed inverse behavior compared to the radiation; that is, the higher the incidence of solar radiation the lower the NDVI, which was a result similar to that found by Souza et al. (2010), Rahman et al. (2015), and Beneduzzi et al. (2017). An exception was stage 8 wheat, which was probably due to cloud cover.

A boxplot analysis of the heights (Figure 4a) showed the presence of seven outliers, but since no model was generated from data points, it was decided to maintain then. A comparison of the NDVI values at different sensor heights, with $1 \mathrm{~m}$ (Figures $4 \mathrm{~b}$ to $4 \mathrm{f}$ ) as the reference, shows similarity between the readings indicating little effect of the height on the readings for wheat at stage 10.5 and soybean at stages R2 and R5, since the values were close to the 1:1 line. For all stages, the values observed at $1.2 \mathrm{~m}$ tended to fall below the $1: 1$ line and those for $0.8 \mathrm{~m}$ tended to fall above the $1: 1$ line; that is, the values for $1.2 \mathrm{~m}$ were slightly underestimated and overestimated for $0.8 \mathrm{~m}$, compared to $1 \mathrm{~m}$.

The similarity between two NDVI measurements was measured with the Willmott index (d) and will increase with the increase in the Willmott index value. The $d$ varied from 0.11 (stage 6 wheat at $1.2 \mathrm{~m}$ ) to 0.79 (stage R5 soybean at $0.8 \mathrm{~m}$ ), therefore showing the highest similarity at stage R5 soybean with a height of $0.8 \mathrm{~m}$, which also showed the smallest MAE and RME. In stage 6 wheat the sensor had a greater effect at its highest height, whereas in stage 8 wheat both the smallest and the greatest height were shown to be influential. In stage 10.5 wheat, this effect was lower for higher NDVI indices, but as noted by Amaral et al. (2015), the saturation of the signal in the red band of the GreenSeeker sensor in the advanced stages may have interfered with the NDVI response. In soybean, in both vegetative stages, the $1.2 \mathrm{~m}$ height had a greater effect and the $0.8 \mathrm{~m}$ height had a minor effect. Thus, we may conclude that the height of the sensor can affect the NDVI depending on the vegetative stage of the plant. 


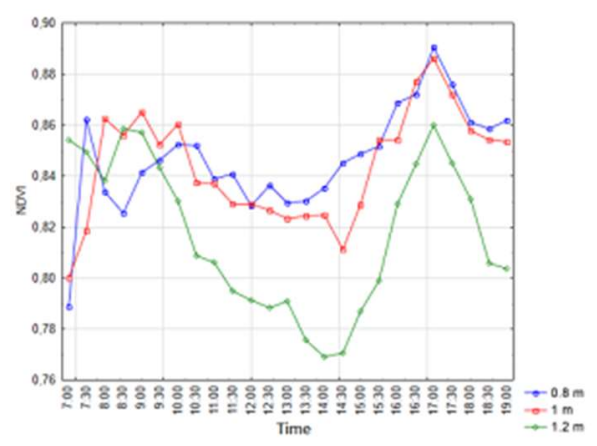

(a) Stage 6 wheat

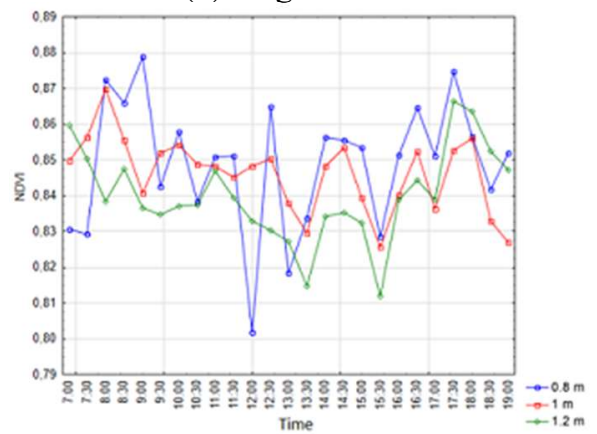

(c) Stage 8 wheat

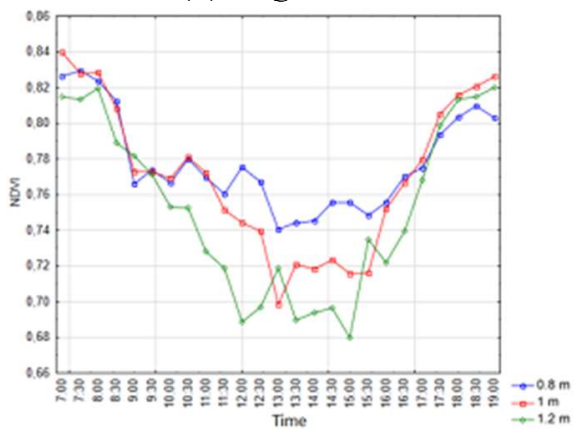

(e) Stage 10.5 wheat

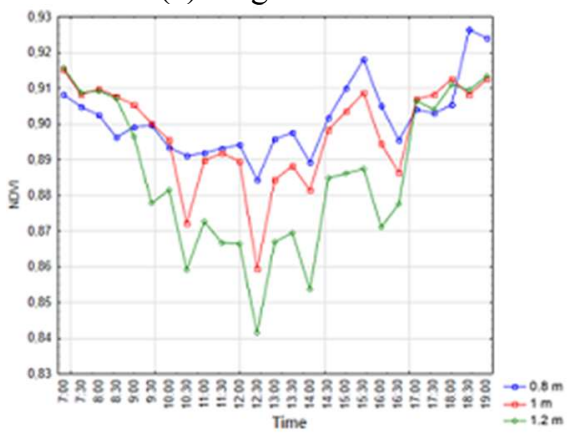

(g) Stage R2 soybean

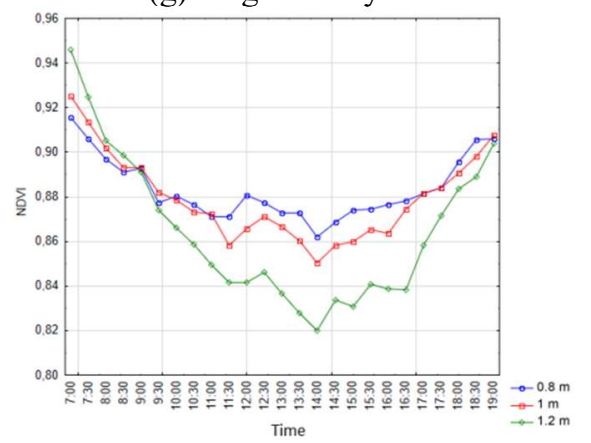

(i) Stage R5 soybean

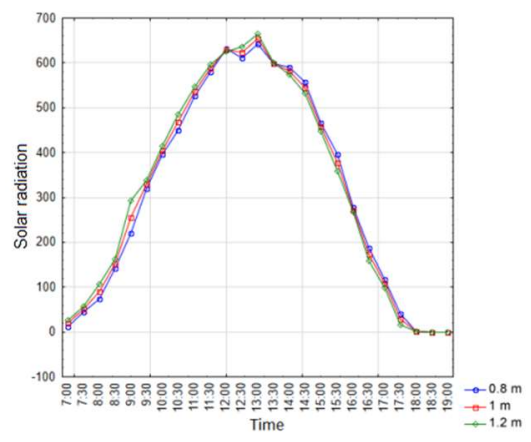

(b) Stage 6 wheat

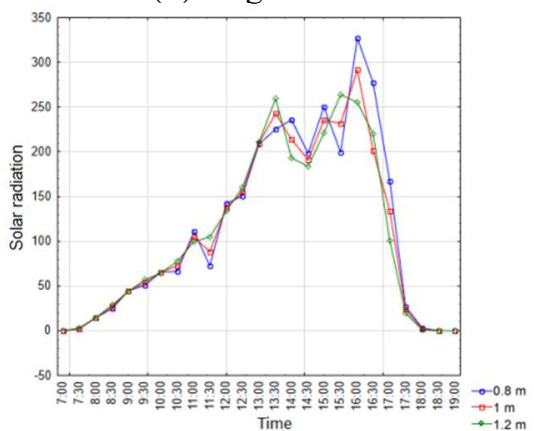

(d) Stage 8 wheat

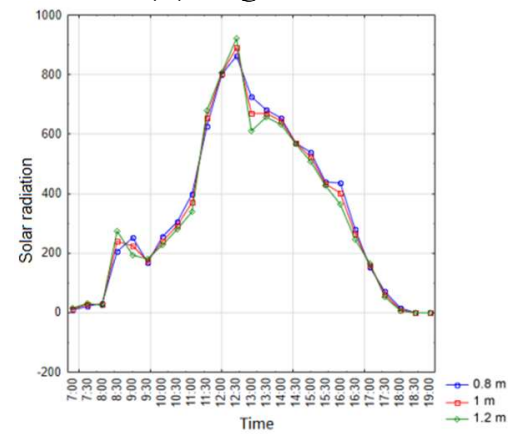

(f) Stage 10.5 wheat

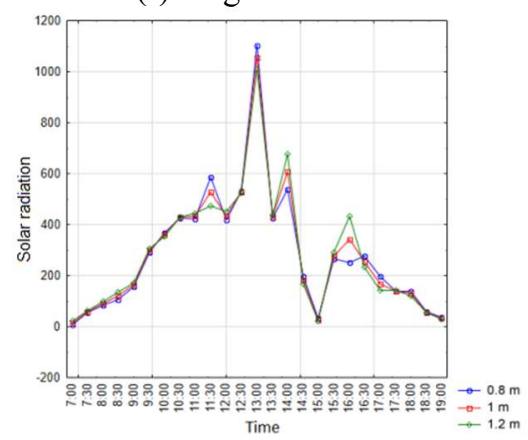

(h) Stage soybean

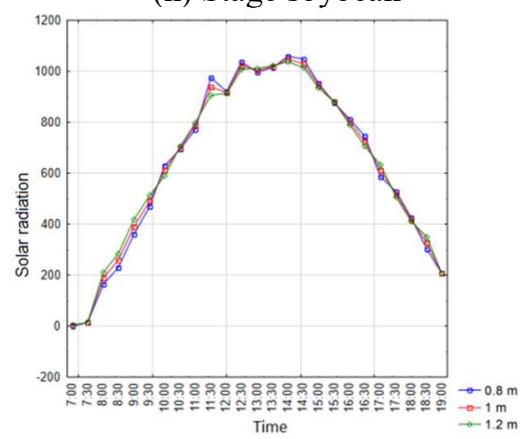

(j) Stage R5 soybean

FIGURE 3. NDVI and solar radiation (SR) as a function of time at three heights $(0.8,1.0$, and $1.2 \mathrm{~m})$ : (a) NDVI stage 6 wheat; (b) SR stage 6 wheat; (c) NDVI stage 8 wheat; (d) SR stage 8 wheat; (e) NDVI stage 10.5 wheat; (f) SR stage 10.5 wheat; (g) NDVI stage R2 soybean; (h) SR stage R2 soybean; (i) NDVI stage R5 soybean; (j) SR stage R5 soybean. 


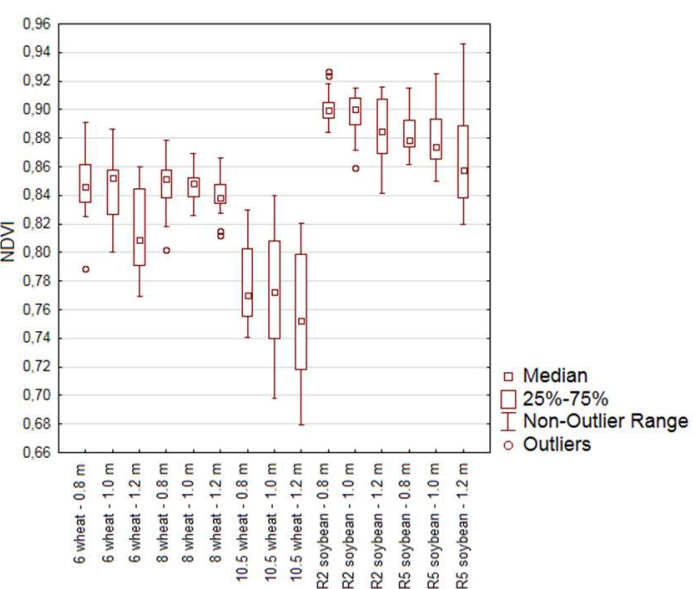

(a)

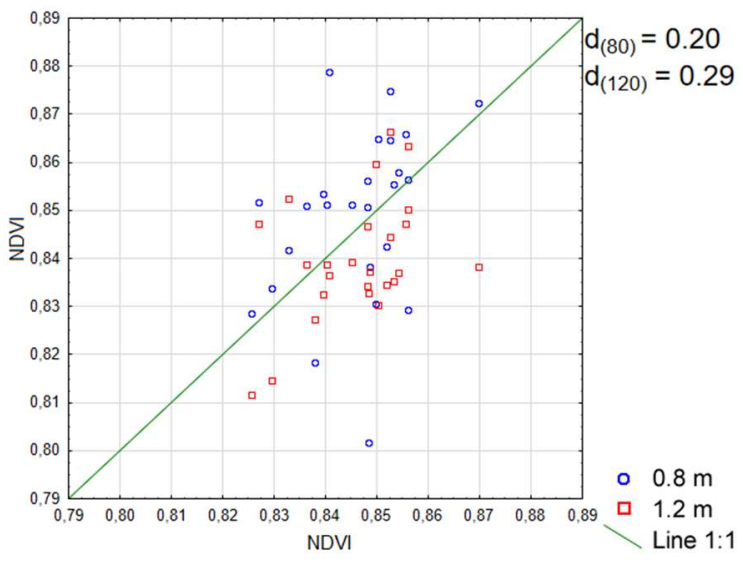

8 wheat

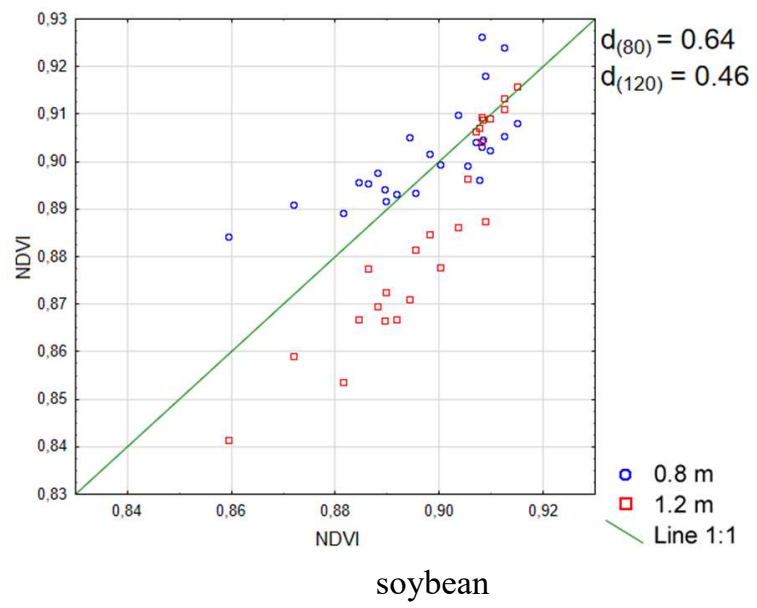

(e) R2

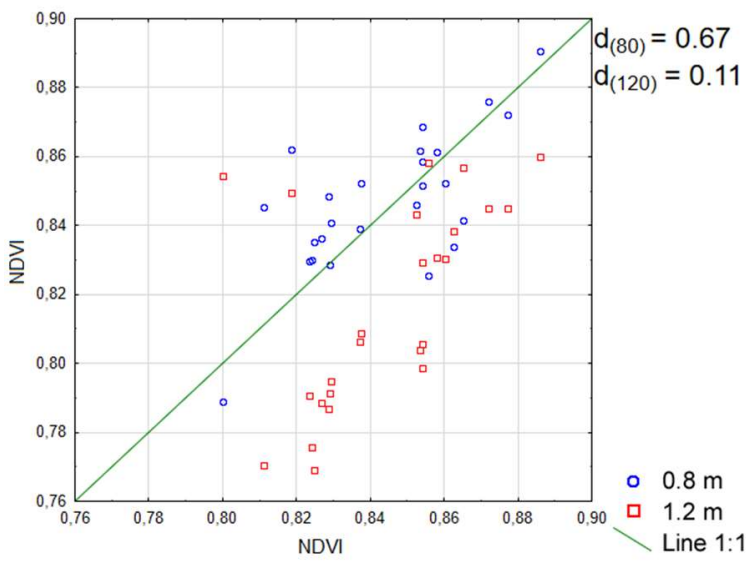

6 wheat

(b) Stage

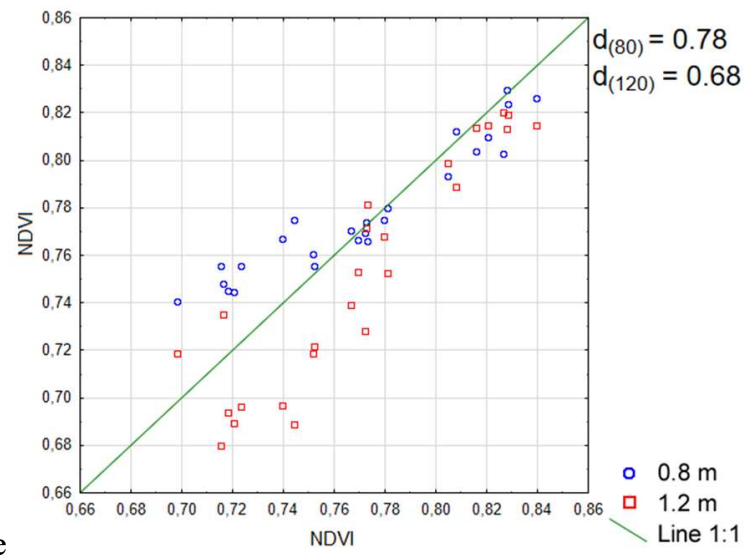

10.5 wheat

(d) Stage

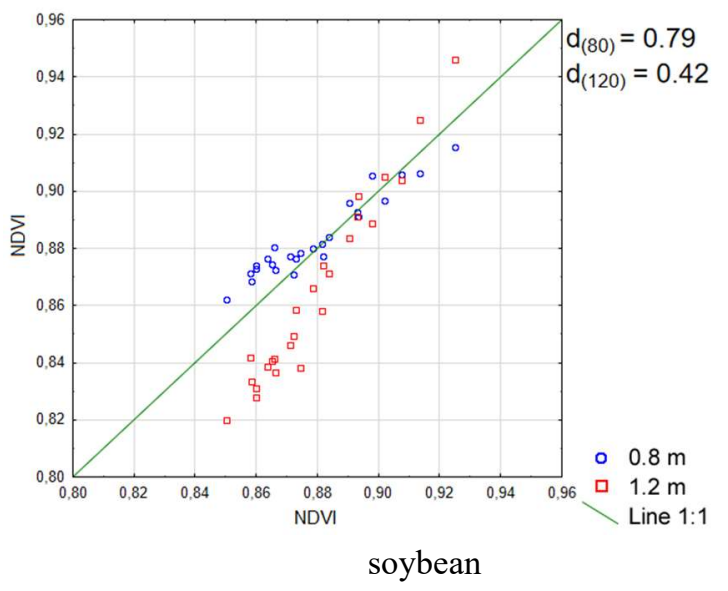

(f) R5

FIGURE 4. Boxplot of NDVI measurements at different crops, growth stages and sensor heights (a) (Ex. 6 wheat-0.8: wheat at stage 6 and sensor at $0.8 \mathrm{~m}$ over canopy). Ratios between $0.8 \mathrm{~m} / 1.0 \mathrm{~m}$ height NDVIs (blue dots) and $0.8 \mathrm{~m} / 1.2 \mathrm{~m}$ height NDVIs (red dots) at stages 6 wheat (b), 8 wheat (c), 10.5 wheat (d), R2 soybean (e), and R5 soybean (f).

As a result of the twist angle of the sensor, the solar radiation obtained by the readings (Figures $5 \mathrm{a}$ to $5 \mathrm{j}$ ) again did not show that the radiation was significantly different for the sensor angles, and an inverse correlation between the solar radiation and the NDVI value was seen. A boxplot analysis of the twist angles (Figure 6a) showed three outliers near the limits of the boxplots that were not apparently correlated. Again, since a model was not generated from data points, it was decided to maintain these values. The NDVI difference charts between twist angles are shown in Figures $6 \mathrm{~b}$ to $6 \mathrm{f}$. 


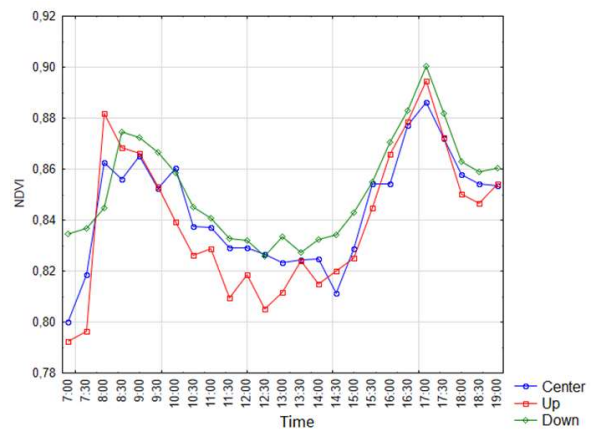

(a) Stage 6 wheat

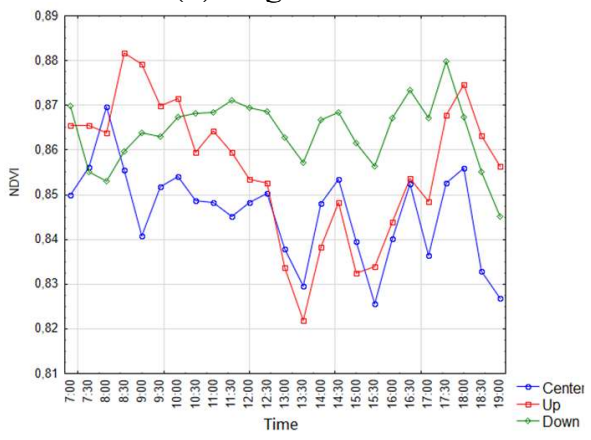

(c) Stage 8 wheat

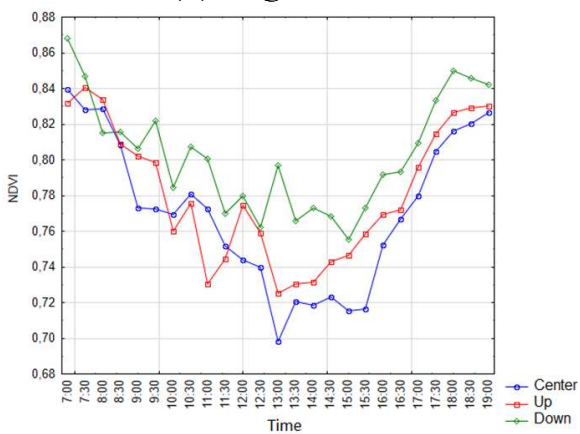

(e) Stage 10.5 wheat

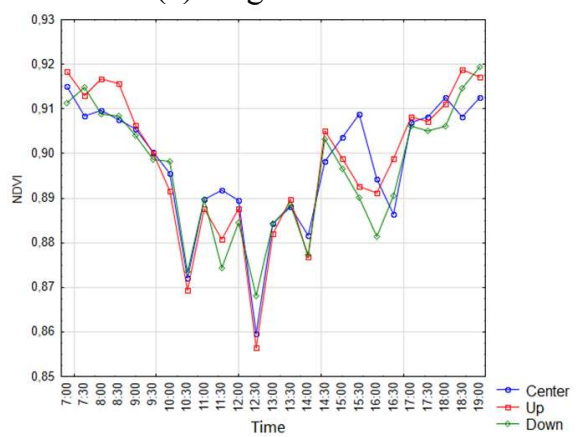

(g) Stage R2 soybean

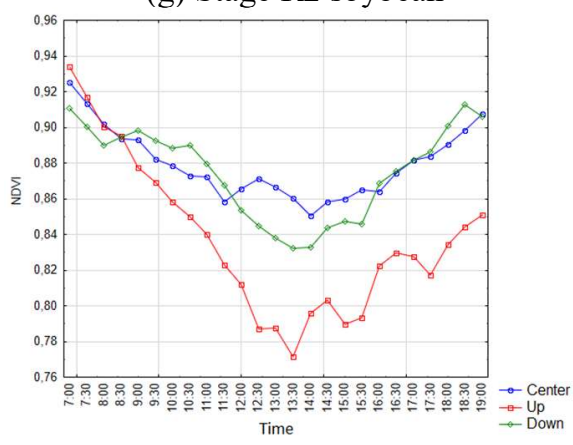

(i) Stage R5 soybean

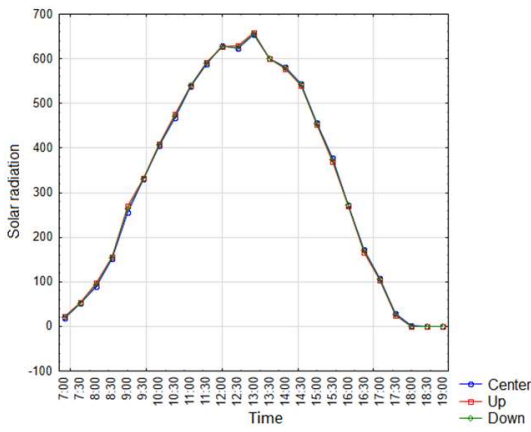

(b) Stage 6 wheat

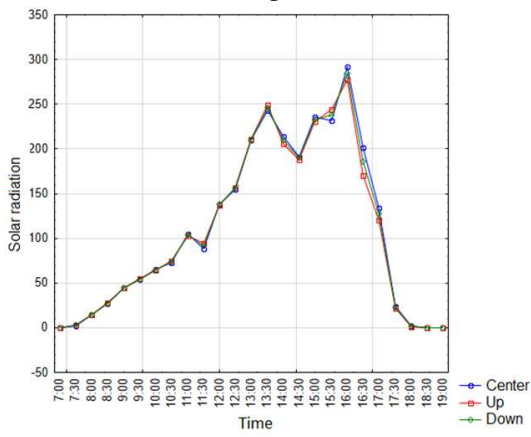

(d) Stage 8 wheat

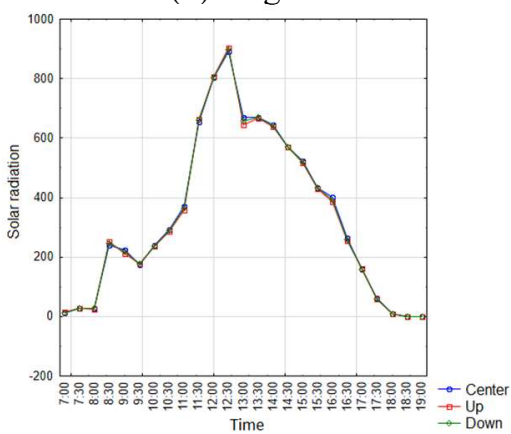

(f) Stage 10.5 wheat

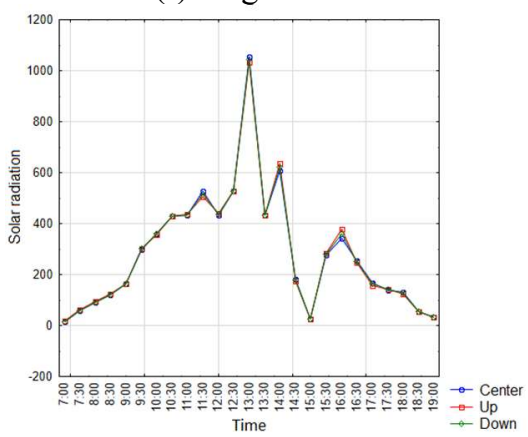

(h) Stage R2 soybean

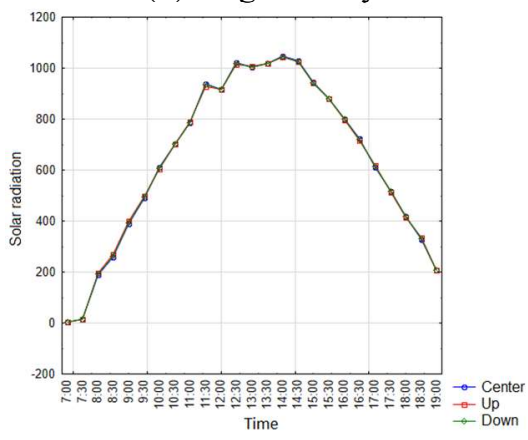

(j) Stage R5 soybean

FIGURE 5. NDVI and solar radiation (SR) as a function of three tilt angles ( $15^{\circ}$ down, center, and $15^{\circ}$ up): (a) NDVI stage 6 wheat; (b) SR stage 6 wheat; (c) NDVI stage 8 wheat; (d) SR stage 8 wheat; (e) NDVI stage 10.5 wheat; (f) SR stage 10.5 wheat; (g) NDVI stage R2 soybean; (h) SR stage R2 soybean; (i) NDVI stage R5 soybean; (j) SR stage R5 soybean. 
In stage 6 wheat (Figure 6b) and stage R2 soybean (Figure 6e), many readings were close to the $1: 1$ line, and high values of $d$ indicated a slight effect of the tilt angle for these stages. In stage 8 wheat (Figure $6 \mathrm{c}$ ), the readings fell at the top of the 1:1 line, which implies that the readings were overestimated when the sensor was positioned upwards and downwards compared to the central position. The values of $d$ were both near 0 , which was consistent with the charts and as seen for the sensor height for stage 8 wheat, there was also an effect of the position on the sensor reading. Tremblay et al. (2008) found a similar result for the NDVI reading in corn with a GreenSeeker sensor, where the wind can change the plant architecture and effect the reading depending of the development stage of the plant.

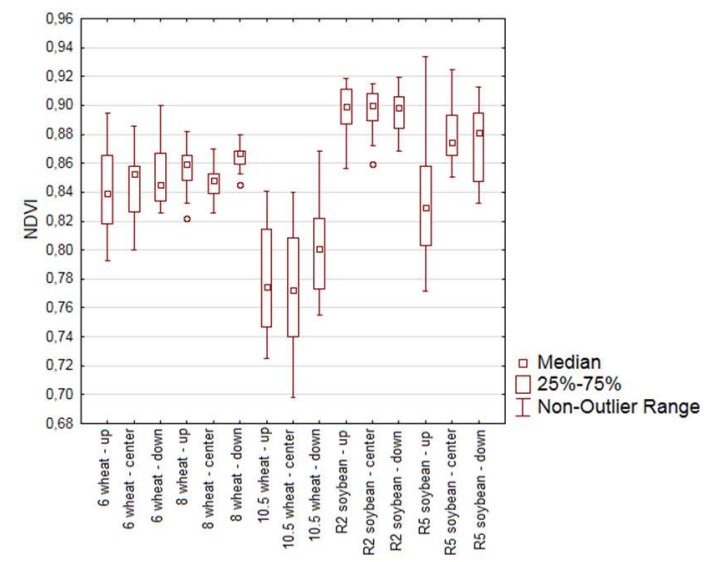

(a)

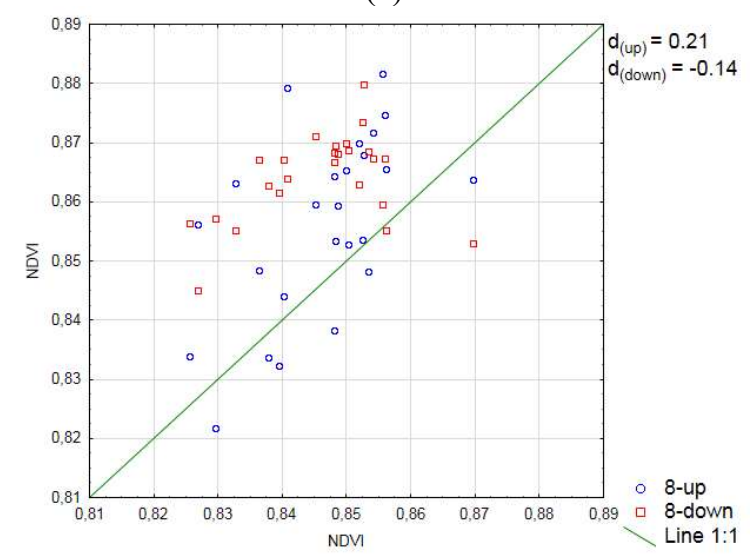

(c) Stage 8 wheat

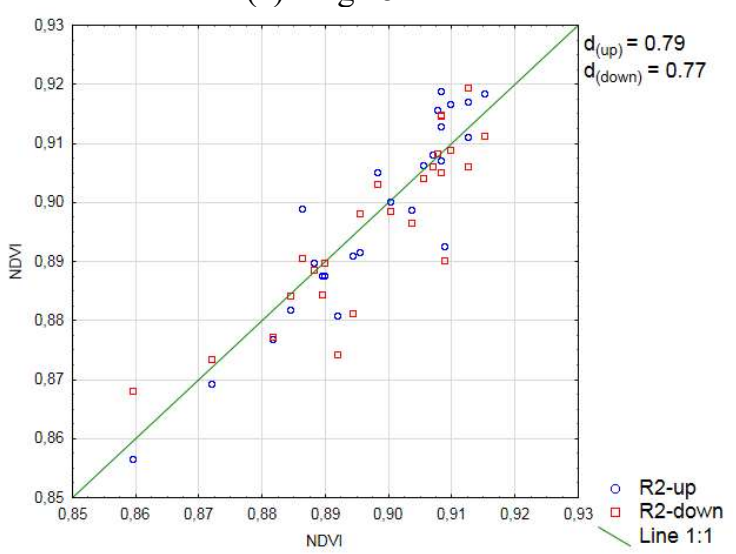

(e) Stage R2 soybean
In stage 10.5 wheat (Figure 6d), the readings again fell close to the 1:1 line but still had a slight tendency to fall near the top. The values of $d$ were 0.76 and 0.52 for a sensor positioned upwards and downwards, which indicated little effect of the sensor tilt angle.

In stage R5 soybean (Figure 6f), the chart indicates the proximity of the readings with the sensor facing down to the $1: 1$ line and a $d$ value of 0.63 , implying a slight effect of this angle on the NDVI, but the sensor facing up shows 22 of the 25 readings were underestimates, and had a d value of -0.28 , which renders the interpretation inconclusive for this position.

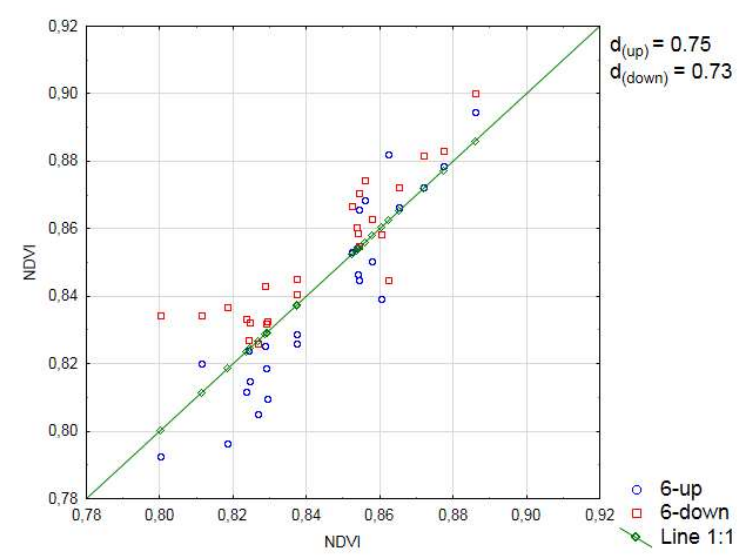

(b) Stage 6 wheat

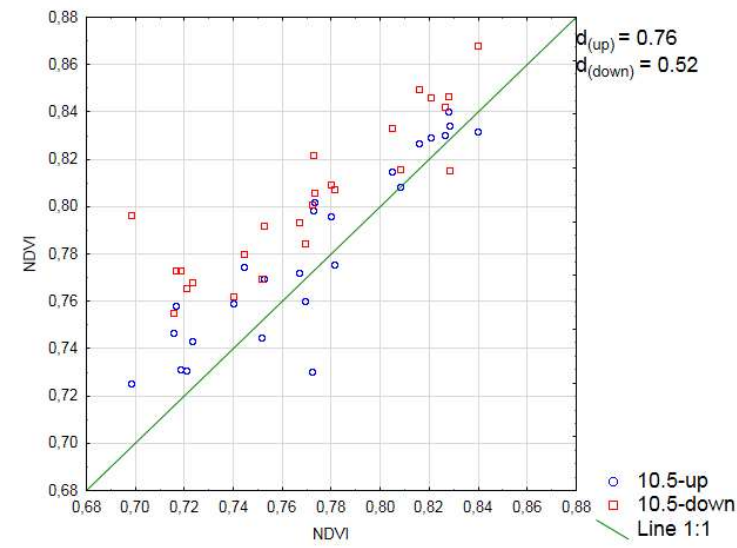

(d) Stage 10.5 wheat

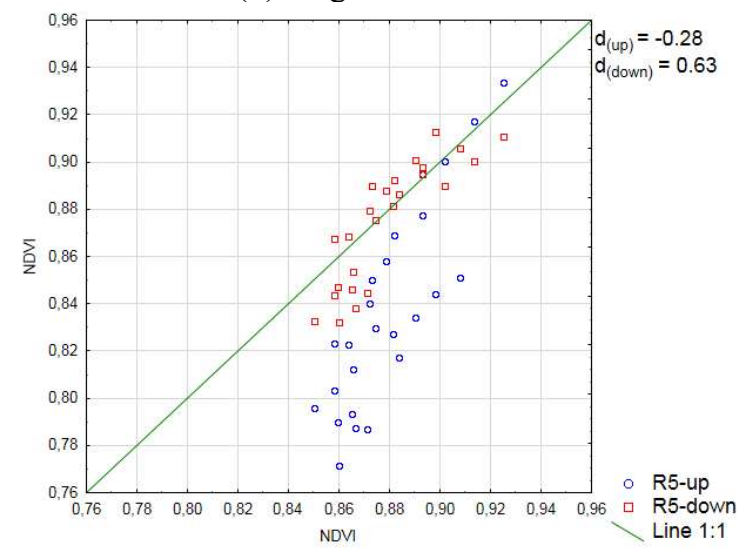

(f) Stage R5 soybean

FIGURE 6. Boxplot of NDVI measurements at different crops, growth stages and tilt angles (a) (Ex. 6 wheat - up: wheat at stage 6 and sensor at $15^{\circ}$ up tilt). Ratios between $15^{\circ}$ up tilt/center NDVIs (blue dots) and $15^{\circ}$ up down tilt/center NDVIs (red dots) at stages 6 wheat (b), 8 wheat (c), 10.5 wheat (d), R2 soybean (e), and R5 soybean (f). 
And in effect of the twist angle of the sensor, similar to the experiments in which the sensor heights and tilt angles were varied, the solar radiation obtained during the readings (Figures $7 \mathrm{a}$ to $7 \mathrm{j}$ ) again did not show that the radiation was significantly different for different sensor angles, and an inverse correlation between the solar radiation and the NDVI value was evident.

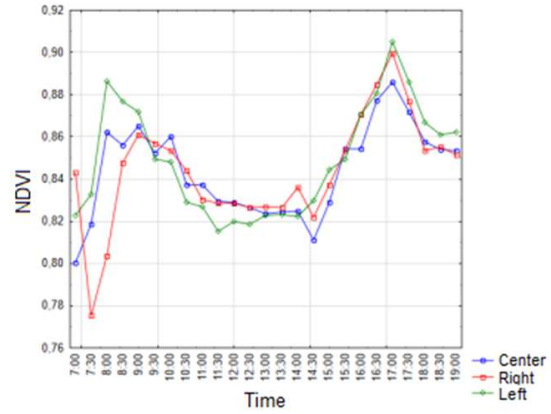

(a) Stage 6 wheat

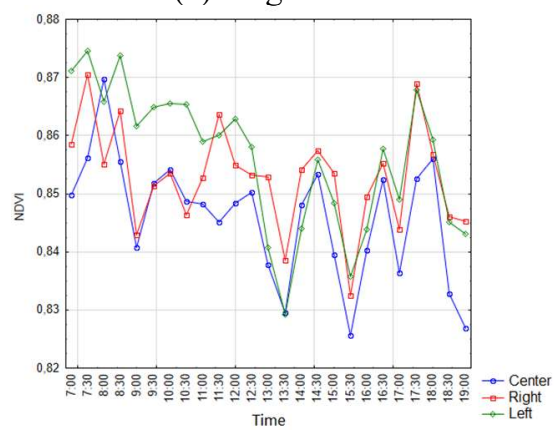

(c) Stage 8 wheat

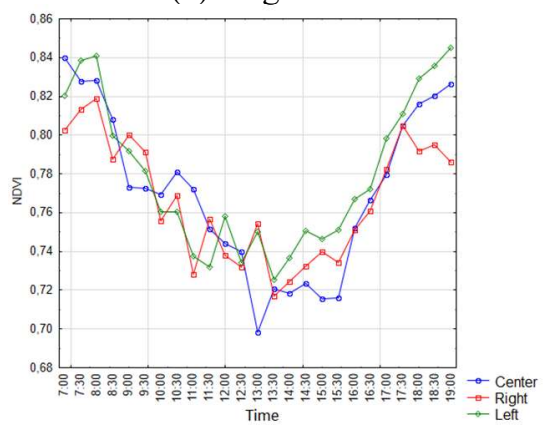

(e) Stage 10.5 wheat

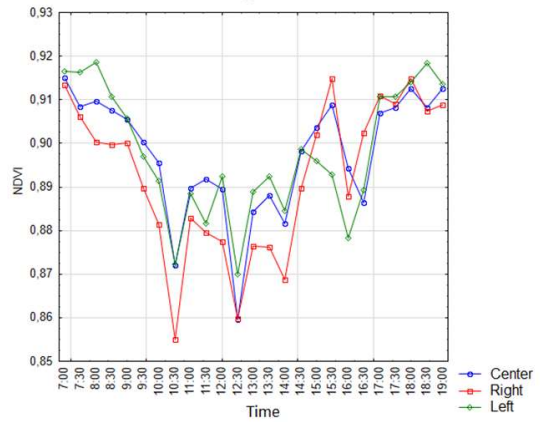

(g) Stage R2 soybean

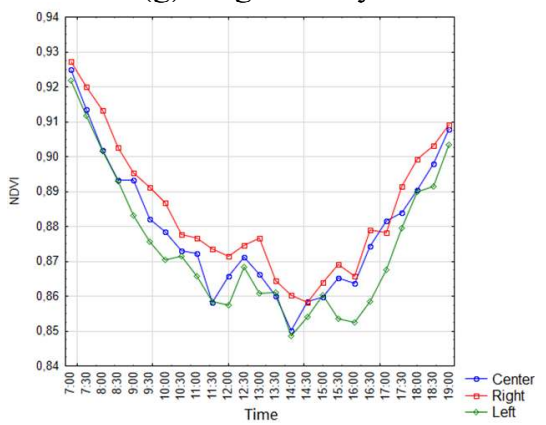

(i) Stage R5 soybean

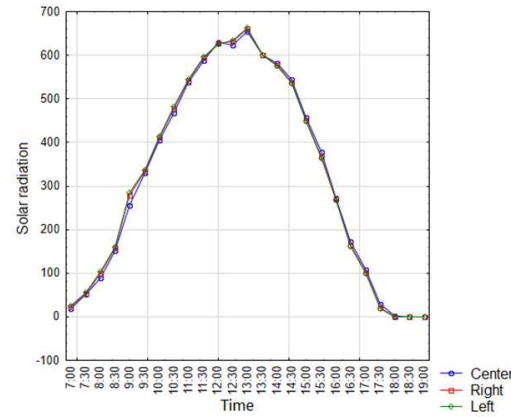

(b) Stage 6 wheat

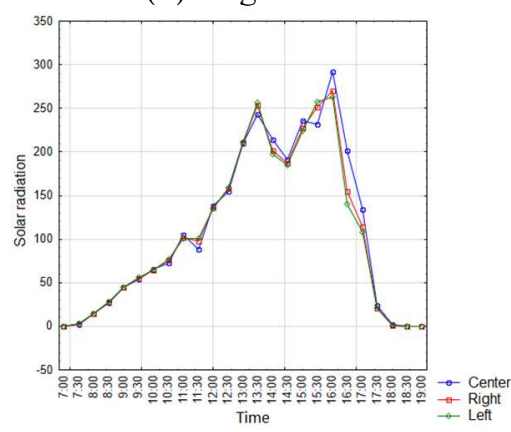

(d) Stage 8 wheat

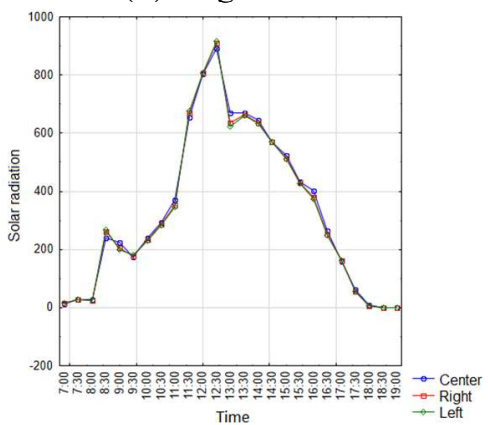

(f) Stage 10.5 wheat

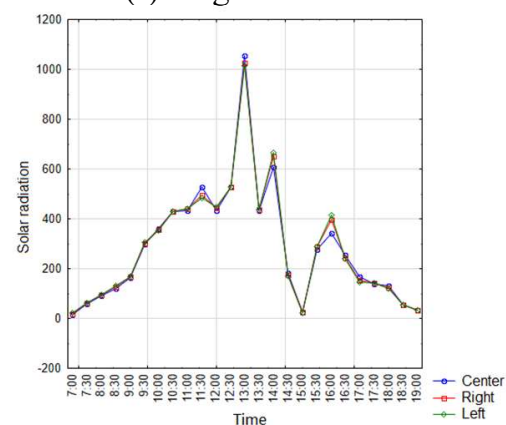

(h) Stage R2 soybean

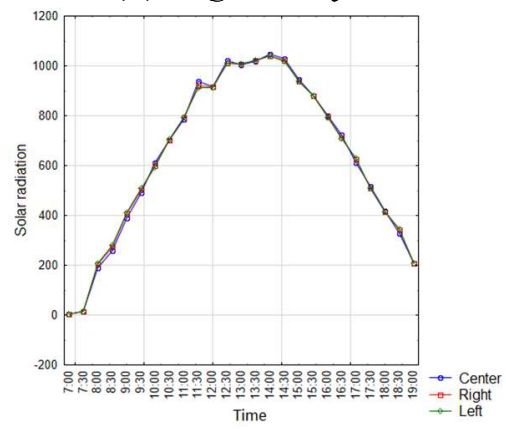

(j) Stage R5 soybean

FIGURE 7. NDVI and solar radiation (SR) as a function of three twist angles ( $15^{\circ}$ left, center, and $15^{\circ}$ right): (a) NDVI stage 6 wheat; (b) SR stage 6 wheat; (c) NDVI stage 8 wheat; (d) SR stage 8 wheat; (e) NDVI stage 10.5 wheat; (f) SR stage 10.5 wheat; (g) NDVI stage R2 soybean; (h) SR stage R2 soybean; (i) NDVI stage R5 soybean; (j) SR stage R5 soybean. 
A boxplot analysis of the twist angles (Figure 8a) showed three outliers for stage 6 wheat, which were the first two readings in the morning, and may have been affected by the position of the sun when the reading was taken, a result similar to that found by Oliveira \& Scharf (2015). Again, since no model was generated from data points, it was decided to maintain then.

For the twist angles of wheat (Figures $8 b$ to $8 d$ ), there is a certain overestimation for both positions in stage 8 wheat, where the lowest values of $\mathrm{d}$ also occurred and

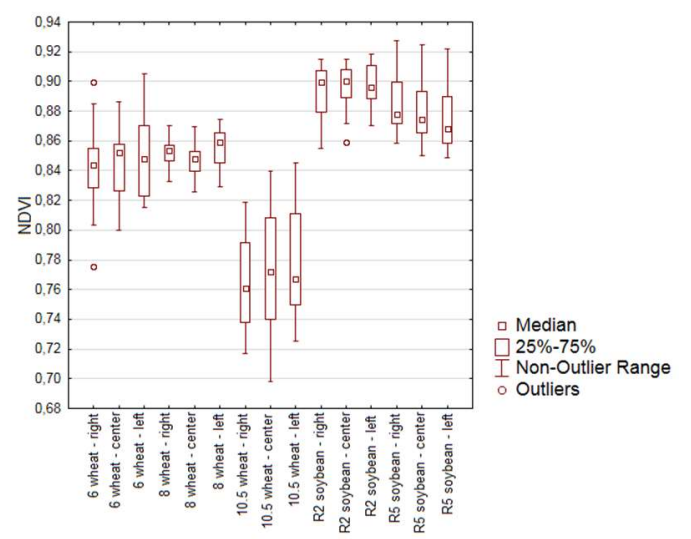

(a)

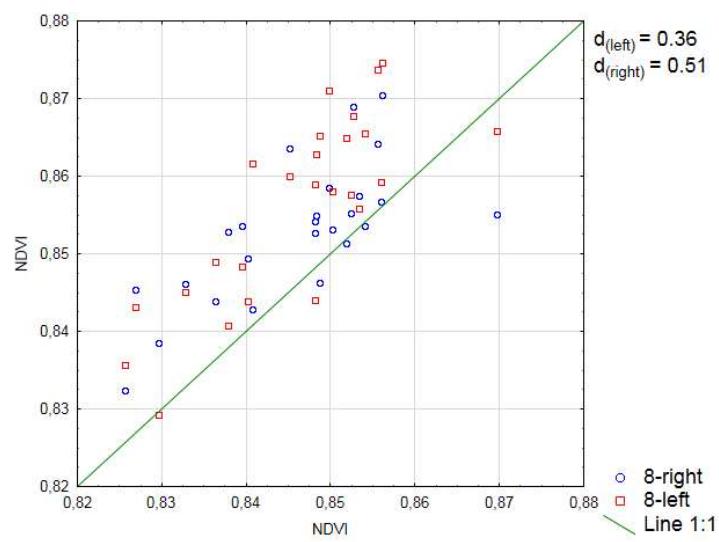

(c) Stage 8 wheat

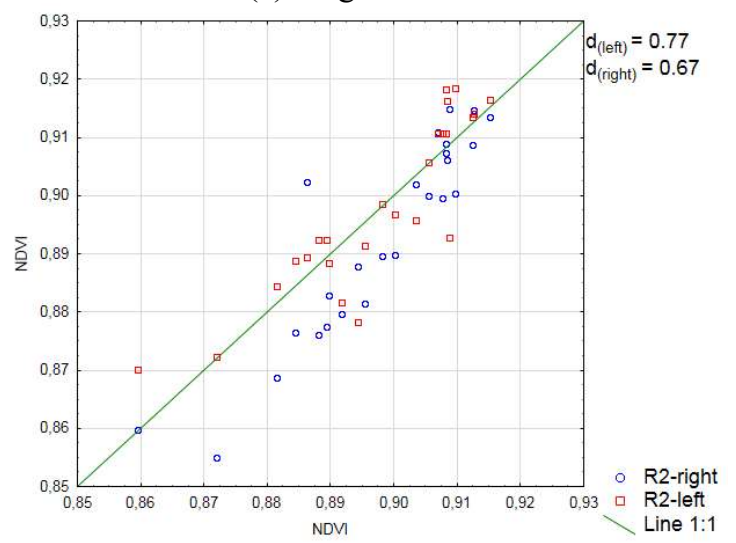

(e) Stage R2 soybean consequently where the position of the sensor had a greater effect on the NDVI, as indicated by a comparison of the sensor heights and twist angles.

In soybeans (Figures 8e and 8f) at both stages, there was an approximation of the reading values with the line was $1: 1$, as well as a value of $d$ near or even higher than 0.7. This shows little effect on the twist position of the sensor on the NDVI. Kim et. al (2010) found a similar result when evaluating the NDVI response to the sensor angle in apple leaves.

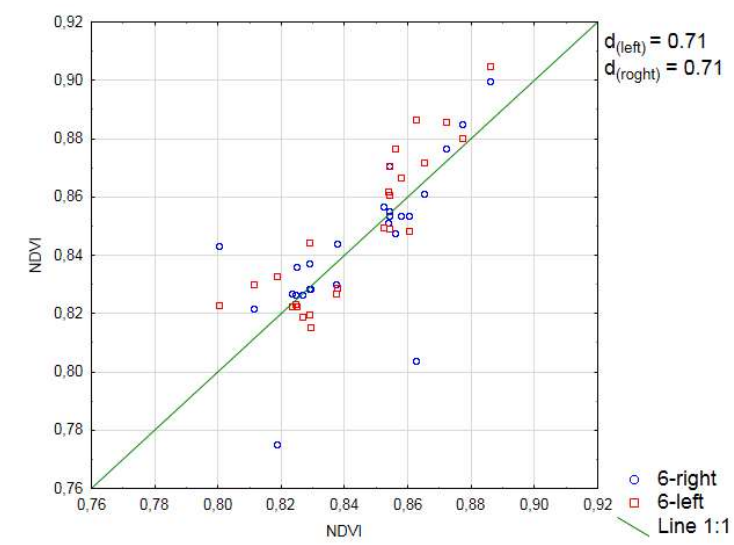

(b) Stage 6 wheat

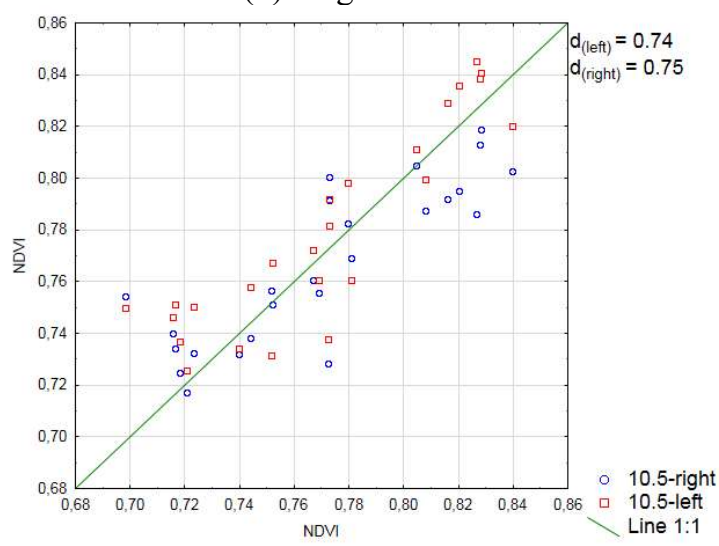

(d) Stage 10.5 wheat

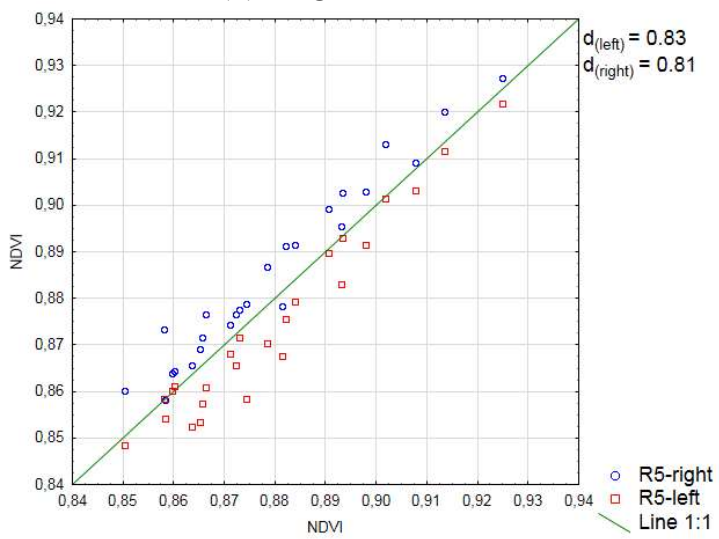

(f) Stage R5 soybean

FIGURE 8. Boxplot of NDVI measurements at different crops, growth stages and twist angles (a) (Ex. 6 wheat - right: wheat at stage 6 and sensor at $15^{\circ}$ right twist). Ratios between $15^{\circ}$ right twist/center NDVIs (blue dots) and $15^{\circ}$ up left twist/center NDVIs (red dots) at stages 6 wheat (b), 8 wheat (c), 10.5 wheat (d), R2 soybean (e), and R5 soybean (f). 


\section{CONCLUSIONS}

The height of the GreenSeeker sensor affected the NDVI depending on the crop and the development stage. This influence was higher at a height of $1.2 \mathrm{~m}$ than at $0.8 \mathrm{~m}$. This result shows that the sensor height specified by the manufacturer (from 0.8 to $1.2 \mathrm{~m}$ ) can affect the reading and that the operator should try to keep the sensor height as fixed as possible. The tilt and twist angles of the sensor did not directly affect the reading under the experimental conditions $\left(15^{\circ}\right.$ for both up/down and right/left).

\section{ACKNOWLEDGMENTS}

The authors are grateful to the Western Paraná State University (UNIOESTE), the Technological Federal University of Paraná (UTFPR), the Araucária Foundation (Fundação Araucária), the Coordination for the Improvement of Higher Education Personnel (CAPES), and the National Council for Scientific and Technological Development (CNPq), for the support received.

\section{REFERENCES}

Alvares CA, Stape JL, Sentelhas PC, de Moraes Gonçalves JL, Sparovek G (2013) Köppen's climate classification map for Brazil. Meteorologische Zeitschrift 22(6):711728. DOI: https://doi.org/10.1127/0941-2948/2013/0507

Amaral LR, Molin JP, Portz G, Finazzi FB, Cortinove L (2015) Comparison of crop canopy reflectance sensors used to identify sugarcane biomass and nitrogen status. Precision Agriculture 16(1):15-28. DOI: https://doi.org/10.1007/s11119-014-9377-2

Beneduzzi HM, Souza EG, Bazzi CL, Schenatto K (2017) Temporal variability in active reflectance sensor-measured NDVI in soybean and wheat crops. Engenharia Agrícola 17(4):771-781. DOI: http://dx.doi.org/10.1590/1809-4430eng.agric.v37n4p771-781/2017

Cao Q, Miao Y, Feng G, Gao X, Li F, Liu B, Yue S, Cheng S, Ustin SL, Khosla R (2015) Active canopy sensing of winter wheat nitrogen status: An evaluation of two sensor systems, Computers and Electronics in Agriculture 112:54-67. DOI:

https://doi.org/10.1016/j.compag.2014.08.012

Cherkasov N, Ibhadon AO, Fitzpatrick P (2015) A review of the existing and alternative methods for greener nitrogen fixation. Chemical Engineering and Processing: Process Intensification 90:24-33. DOI: http://dx.doi.org/10.1016/j.cep.2015.02.004

Crusiol LGT, Neiverth W, Rio A, Sibaldelli RNR, Ferreira LC, Carvalho JFC, Nepomuceno AL, Neumaier N, Farias JRB (2013) Interferências metodológicas nos valores de NDVI: Posicionamento do sensor e área amostral. In: Jornada Acadêmica da Embrapa Soja. Londrina, Embraba Soja. Proceedings...

Drake MP, Vann MC, Fisher LR (2015) Effect of nitrogen application rate on the yield, quality, and chemical components of flue-cured tobacco, part II: application method. Tobacco Science 52:26-34. DOI:

https://doi.org/10.3381/14-043
Embrapa - Empresa Brasileira de Pesquisa Agropecuária (2018) Sistema de classificação dos solos. Brasília, Embrapa, 5 ed.

Hubert M, Van der Veeken S (2008) Outlier detection for skewed data. Journal of Chemometrics: A Journal of the Chemometrics Society 22(3-4):235-246.

Pimentel FG, Garcia GH (2002) Estatística aplicada a experimentos agronômicos e florestais. Piracicaba, Biblioteca de Ciências Agrárias Luiz de Queiroz, 307p.

Kim Y, Glenn DM, Park J, Ngugi Hk, Lehman BL (2010) Active Spectral Sensor Evaluation under Varying Conditions. ASABE Annual International Meeting. DOI: http://dx.doi.org/10.13031/2013.29813

Oliveira LF, Scharf PC (2015) Diurnal variability in reflectance measurements from cotton. Crop Science 54(4):1769-1781. DOI:

http://dx.doi.org/10.2135/cropsci2013.04.0217

Padilla FM, Peña-fleitas MT, Gallardo M, Thompson RB (2014) Threshold values of canopy reflectance indices and chlorophyll meter readings for optimal nitrogen nutrition of tomato. Applied Biology 166(2):271-285. DOI: http://dx.doi.org/10.1111/aab.12181

Rahman MM, Lamb DW, Stanley JN (2015) The impact of solar illumination angle when using active optical sensing of NDVI to infer fAPAR in a pasture canopy. Agricultural and Forest Meteorology 202(15):39-43. DOI: https://doi.org/10.1016/j.agrformet.2014.12.001

Ritchie SW, Hanway JJ, Thompson HE (1985) How a soybean plant develops. Iowa State University, v. 53.

Schwerz F, Caron BO, Elli EF, Oliveira DM, Monteiro GC, Souza VQ (2016) Avaliação do efeito de doses e fontes de nitrogênio sobre variáveis morfológicas, interceptação de radiação e produtividade do girassol. Revista Ceres 63(3):380-386. DOI: https://dx.doi.org/10.1590/0034-737X201663030015

Souza EG, Scharf PC, Sudduth K (2010) Sun position and cloud effects on reflectance and vegetation indices of corn. Agronomy Journal 102(2):734-744. DOI:

http://dx.doi.org/10.2134/agronj2009.0206

Schieffer J, Dillon C (2015) The economic and environmental impacts of precision agriculture and interactions with agro-environmental policy. Precision Agriculture 16(1):46-61. DOI: http://dx.doi.org/10.1007/s11119-014-9382-5

Schmitt MA, Lamb JA, Randall GW, Orf JH, Rehm GW (2001) In-Season Fertilizer Nitrogen Applications for Soybean in Minnesota. Agronomy Journal 93(5):83-988. DOI: http://dx.doi.org/10.2134/agronj2001.935983x

Singh M, Kumar R, Sharma A, Singh B, Thind SK (2015) Calibration and Algorithm Development for Estimation of Nitrogen in Wheat Crop Using Tractor Mounted N-Sensor. The Scientific World Journal 2015:12pages. DOI: http://dx.doi.org/10.1155/2015/163968 
Tremblay N, Wang Z, Ma B, Belec C, Vigneault P (2008) A comparison of crop data measured by two commercial sensors for variable-rate nitrogen application. Precision Agriculture 10:145. DOI: https://doi.org/10.1007/s11119008-9080-2

Tubana B, Harrell D, Walker T, Teboh J, Lofton J, Kanke Y, Philips S (2011) Relationships of spectral vegetation indices with rice biomass and grain yield at different sensor view angles. Agronomy Journal 103(5):1405-1413. DOI: http://dx.doi.org/10.2134/agronj2011.0061
Walsh OS, Klatt AR, Solie JB, Godsey CB, Raun WR (2012) Use of soil moisture data for refined GreenSeeker sensor based nitrogen recommendations in winter wheat (Triticum aestivum L.). Precision Agriculture 14(3):343356. DOI: http://dx.doi.org/10.1007/s11119-012-9299-9

Willmott CJ, Robeson SM, Matsuura K (2012) A Refined Index of Model Performance. International Journal of Climatology 32(13): 2088-2094. DOI: http://dx.doi.org/10.1002/joc.2419 